\title{
Thermostructural Analysis of Plate-Type Heat Exchanger Prototypes Considering Weld Properties
}

\author{
Kee-nam Song and Sung-deok Hong \\ VHTR Technology Development Group, Korea Atomic Energy Research Institute, 1045 Daedeok-daero, Yusong-gu, \\ Daejeon 305353, Republic of Korea \\ Correspondence should be addressed to Kee-nam Song, knsong@kaeri.re.kr
}

Received 9 August 2012; Revised 16 November 2012; Accepted 16 November 2012

Academic Editor: Leon Cizelj

Copyright ( $\odot 2012$ K.-n. Song and S.-d. Hong. This is an open access article distributed under the Creative Commons Attribution License, which permits unrestricted use, distribution, and reproduction in any medium, provided the original work is properly cited.

\begin{abstract}
The mechanical properties in a weld zone are different from those in the parent material owing to their different microstructures and residual weld stresses. Welded plate-type heat exchanger prototypes made of Hastelloy-X alloy were manufactured, and performance tests on the prototypes were performed in a small-scale nitrogen gas loop at the Korea Atomic Energy Research Institute. Owing to a lack of mechanical properties in the weld zone, previous research on the strength analyses of the prototypes was performed using the parent material properties. In this study, based on the mechanical properties of Hastelloy-X alloy obtained using an instrumented indentation technique, strength analyses considering the mechanical properties in the weld zone were performed, and the analysis results were compared with previous research. As a result of the comparison, a thermostructural analysis considering the weld material properties is needed to understand the structural behavior and evaluate the structural integrity of the prototype more reliably.
\end{abstract}

\section{Introduction}

Researches demonstrating the massive production of hydrogen using a very high temperature reactor (VHTR) designed for operation at up to $950^{\circ} \mathrm{C}$ have been actively carried out worldwide. In the intermediate loop of a nuclear hydrogen program as shown in Figure 1, a process heat exchanger (PHE) is a key component for transferring the high heat generated in a very high temperature reactor to a chemical reaction yielding a large quantity of hydrogen. The Korea Atomic Energy Research Institute (KAERI) has recently established a small-scale nitrogen gas loop [1] for the performance test of VHTR components and has manufactured two kinds of welded plate-type PHE prototypes, a $3 \mathrm{~kW}$ class and a $10 \mathrm{~kW}$ class, made of Hastelloy-X alloy.

Figure 2 shows the overall dimensions of the two types of plate-type PHE prototypes, and their inner components. Grooves $1.0 \mathrm{~mm}$ in diameter are machined into the flow plate for the primary coolant (nitrogen gas) as shown in Figure 3(a). Waved channels are bent into the flow plate for the secondary coolant $\left(\mathrm{SO}_{3}\right.$ gas) as shown in Figure 3(b).
Twenty flow plates for the primary and secondary coolants are stacked in turn for the $3 \mathrm{~kW}$ class plate-type PHE prototype, and forty flow plates for the primary and secondary coolants are stacked in turn for the $10 \mathrm{~kW}$ class plate-type PHE prototype. The flow plates are also bonded along the edge of the flow plate using a solid-state diffusion bonding method. After stacking and bonding the flow plates, the outside of the PHE prototypes is covered with a Hastelloy-X alloy plate $3.0 \mathrm{~mm}$ thick and is welded along its edges using gas tungsten arc welding with argon as a shielding gas.

The microstructures in the weld zone, including the weld (or fusion zone) and heat-affected zone (HAZ), are different from those in the parent material, as shown in Figure 4 [2]. Consequently, the mechanical properties in the weld zone are different from those in the parent material to a certain degree owing to different microstructures and residual welding stresses. When a welded structure is loaded, the mechanical behavior of the welded structure might differ from the case of a structure with homogeneous mechanical properties. Nonetheless, structural analyses [3-7] of the plate-type PHE prototypes were carried out using only the parent material 


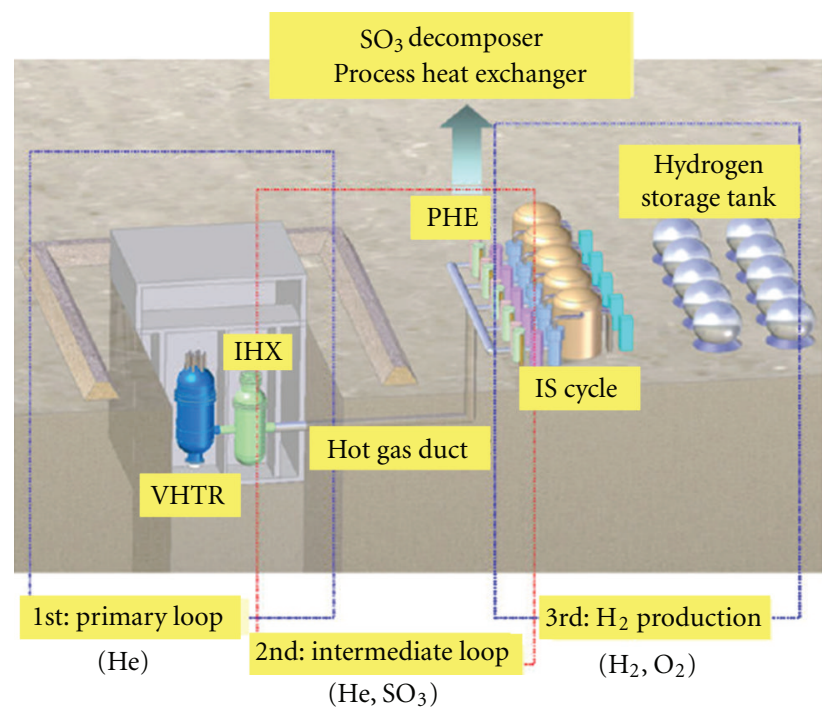

FIGURE 1: Nuclear hydrogen system.

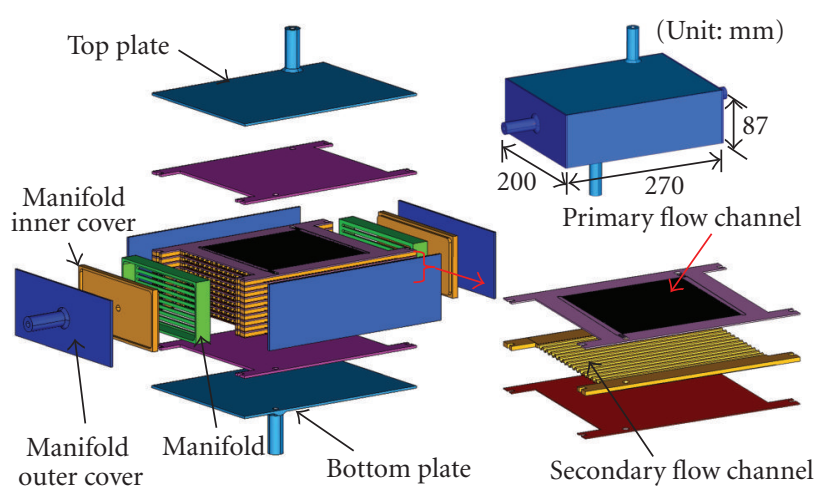

(a)

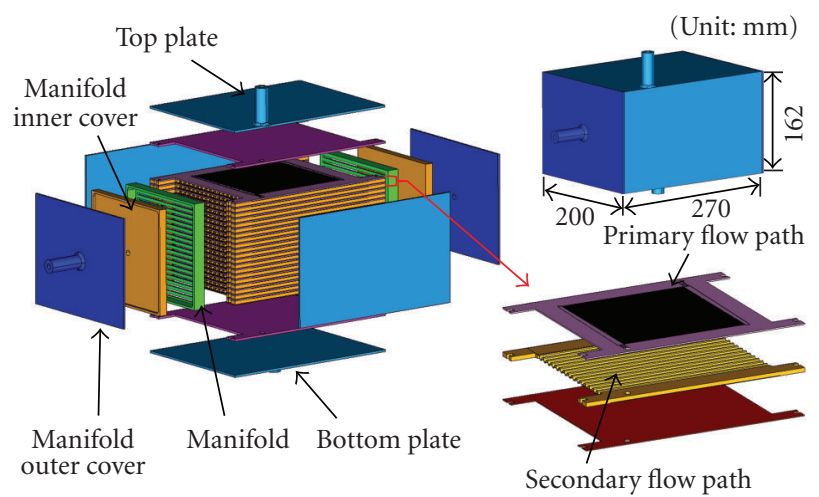

(b)

FIGURE 2: Overall dimension and parts of the plate-type PHE prototypes: (a) $3 \mathrm{~kW}$ class PHE prototype and (b) $10 \mathrm{~kW}$ class PHE prototype.

properties owing to a lack of mechanical properties in the weld zone. Usually, the best way to obtain the mechanical properties in the weld zone is by taking tensile test specimens from the fusion zone and HAZ, and by performing a standard tensile test. However, when the weld zone is very narrow and the interfaces are not clear, it is difficult to take tensile test specimens from the weld zone. The reason for this is that the mechanical properties in the base material are usually used for structural analyses of the welded structure. As an aside, it has recently been determined that the ball indentation technique has the potential to be an excellent substitute for a standard tensile test, especially in the case of small specimens or property-gradient materials such as welds [8]. The weld mechanical properties of the Hastelloy-X plate were then obtained [9] using an instrumented indentation technique.

In this study, to investigate the effect of the weld material properties on the mechanical behavior of the platetype PHE prototypes, strength analyses considering the weld mechanical properties obtained using an instrumented
TABle 1: Nominal chemical composition (wt\%) of Hastelloy-X alloy.

\begin{tabular}{cccccccccc}
\hline $\mathrm{Ni}$ & $\mathrm{Cr}$ & $\mathrm{Fe}$ & $\mathrm{Mo}$ & $\mathrm{Co}$ & $\mathrm{W}$ & $\mathrm{C}$ & $\mathrm{Mn}$ & $\mathrm{Si}$ & $\mathrm{B}$ \\
\hline 47 & 22 & 18 & 9 & 1.5 & 0.6 & 0.10 & 1 & 1 & 0.008 \\
\hline
\end{tabular}

indentation technique are performed, and the analysis results are compared with previous research using only the parent material properties.

\section{Weld Material Properties}

Hastelloy-X is a nickel-chromium-iron-molybdenum alloy that possesses an exceptional combination of oxidation resistance, fabricability, and high-temperature strength. The chemical composition, physical properties, and mechanical properties of Hastelloy-X alloy extracted from a website [11] are summarized in Tables 1, 2, and 3, respectively. Figure 5 shows one of the specimens taken from the welded Hastelloy$\mathrm{X}$ alloy plate and its indented positions for determining 


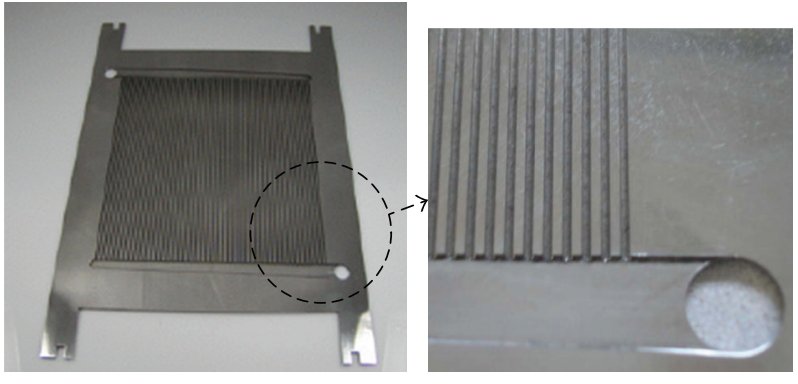

(a)

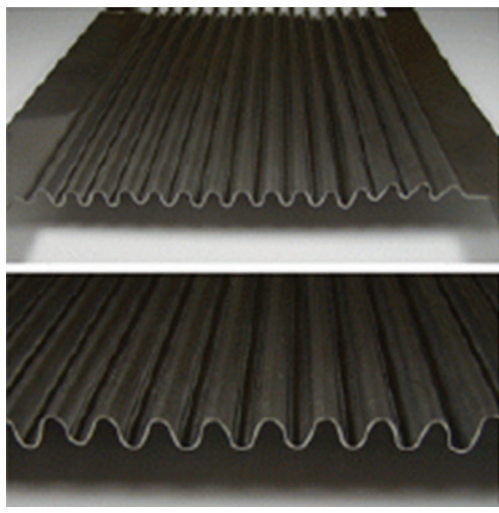

(b)

Figure 3: Flow plates of plate-type PHE prototypes: (a) primary flow plate and (b) secondary flow plate.

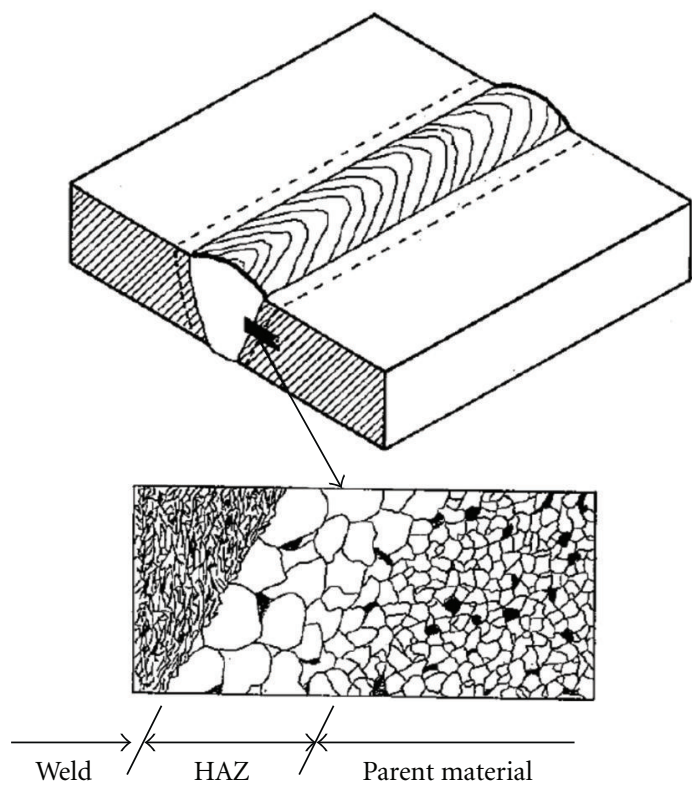

FIGURE 4: Microstructure near the weld [2].
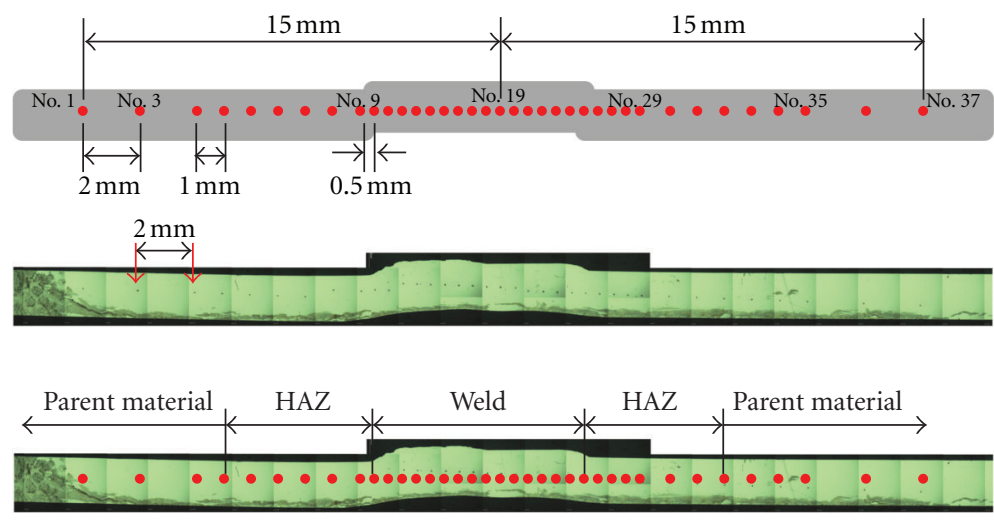

FIgURE 5: Indented position in a welded Hastelloy-X alloy strip [10]. 
TABLe 2: Physical properties of Hastelloy-X alloy.

\begin{tabular}{lccccc}
\hline $\begin{array}{l}\text { Temperature } \\
\left({ }^{\circ} \mathrm{C}\right)\end{array}$ & $\begin{array}{c}\text { Modulus of } \\
\text { elasticity }(\mathrm{GPa})\end{array}$ & $\begin{array}{c}\text { Poisson's } \\
\text { ratio }\end{array}$ & $\begin{array}{c}\text { Thermal conductivity } \\
\left(\mathrm{W} / \mathrm{m} \cdot{ }^{\circ} \mathrm{C}\right)\end{array}$ & $\begin{array}{c}\text { Specific heat } \\
(\mathrm{J} / \mathrm{kg} \cdot \mathrm{K})\end{array}$ & $\begin{array}{c}\text { Coefficient of thermal } \\
\text { expansion }\left(10^{-6} /{ }^{\circ} \mathrm{C}\right)\end{array}$ \\
\hline 20 & 205 & 0.3 & 11.6 & 486 & - \\
100 & 202 & 0.3 & 12.9 & 490 & 13.3 \\
200 & 195 & 0.3 & 14.6 & - & 14.0 \\
300 & 190 & 0.3 & 16.3 & 494 & 14.3 \\
400 & 183 & 0.3 & 17.9 & 498 & 14.5 \\
500 & 177 & 0.3 & 19.5 & - & 15.7 \\
600 & 168 & 0.3 & 21.1 & 515 & 1 \\
700 & 161 & 0.3 & 22.9 & - & 15.7 \\
800 & 153 & 0.3 & 24.6 & 26.3 & 16.3 \\
900 & 145 & 0.3 & 27.9 & 544 & 16.7 \\
1000 & 135 & 0.3 & & \\
\hline
\end{tabular}
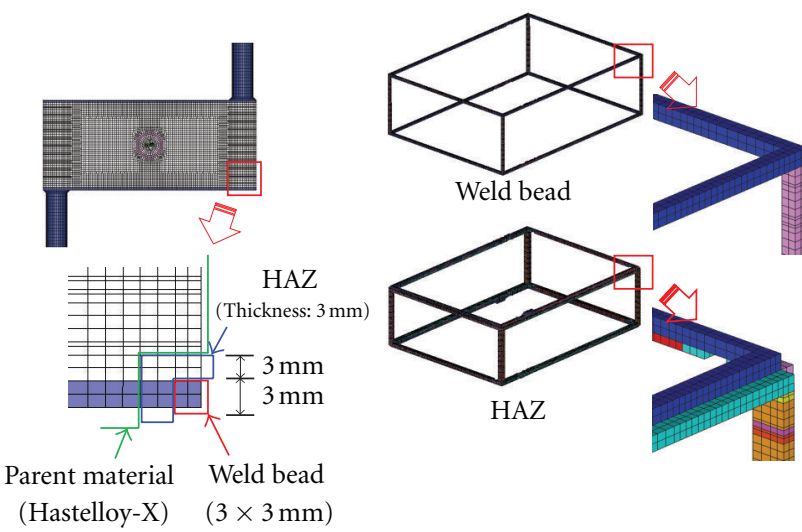

(a)
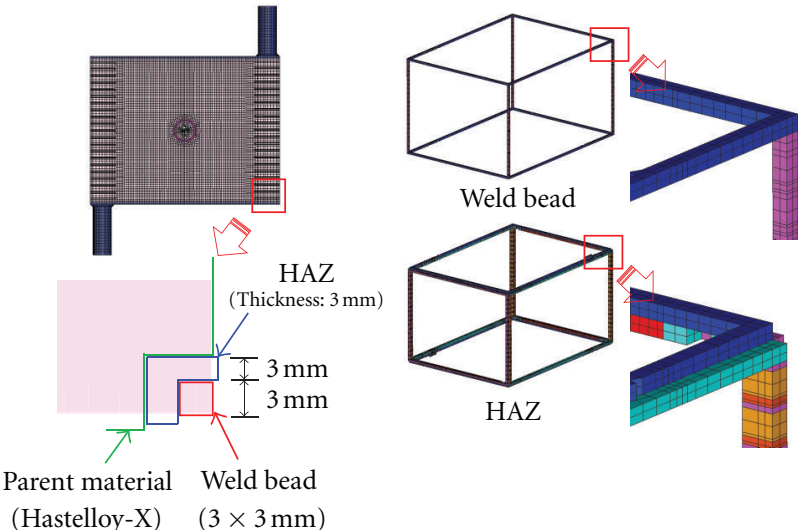

(Hastelloy-X) $\quad(3 \times 3 \mathrm{~mm})$

(b)

FIgure 6: FE models in the weld: (a) $3 \mathrm{~kW}$ class PHE prototype and (b) $10 \mathrm{~kW}$ class PHE prototype.

TABLE 3: Mechanical properties of Hastelloy-X alloy.

\begin{tabular}{lcc}
\hline $\begin{array}{l}\text { Temperature } \\
\left({ }^{\circ} \mathrm{C}\right)\end{array}$ & $\begin{array}{c}\text { Yield stress } \\
(\mathrm{MPa})\end{array}$ & $\begin{array}{c}\text { Ultimate tensile strength } \\
(\mathrm{MPa})\end{array}$ \\
\hline 20 & 379 & 767 \\
538 & 245 & 614 \\
649 & 244 & 581 \\
760 & 237 & 463 \\
871 & 194 & 310 \\
982 & 91 & 177 \\
1093 & 43 & 97 \\
\hline
\end{tabular}

the mechanical properties of the parent material, weld (or fusion zone), and HAZ of the Hastelloy-X alloy strip with a $3 \mathrm{~mm}$ thickness. Since the measured mechanical properties have certain variations in each zone, it is necessary to set a reference value in each zone. In this study, an average value is set as the reference value in each zone. The average values of the mechanical properties in the parent material, weld, and HAZ of the welded Hastelloy-X alloy strip are obtained using the measured data. Based on the average mechanical
TABle 4: Normalized mechanical properties of Hastelloy-X alloy.

\begin{tabular}{lcc}
\hline & Yield stress & Ultimate tensile strength \\
\hline Parent material & 1.000 & 1.000 \\
HAZ & 0.962 & 0.998 \\
Weld & 1.094 & 1.120 \\
\hline
\end{tabular}

properties in the parent material of the Hastelloy-X alloy strip, normalizing factors are obtained in the weld (or fusion zone) and HAZ to be later utilized in a strength analysis. Table 4 shows the normalizing factors, in other words, the normalized mechanical properties, of the parent material, weld, and HAZ on the weld cross-section of the weld mockup [10]. According to Table 4, the mechanical properties in the weld, HAZ, and parent material differ to a certain degree and therefore might affect the structural behavior of the platetype PHE prototypes when considering the weld mechanical properties. The weld mechanical properties used in this study therefore include the effect of different microstructures as well as the residual welding stress, as they were obtained from the weld specimen. 


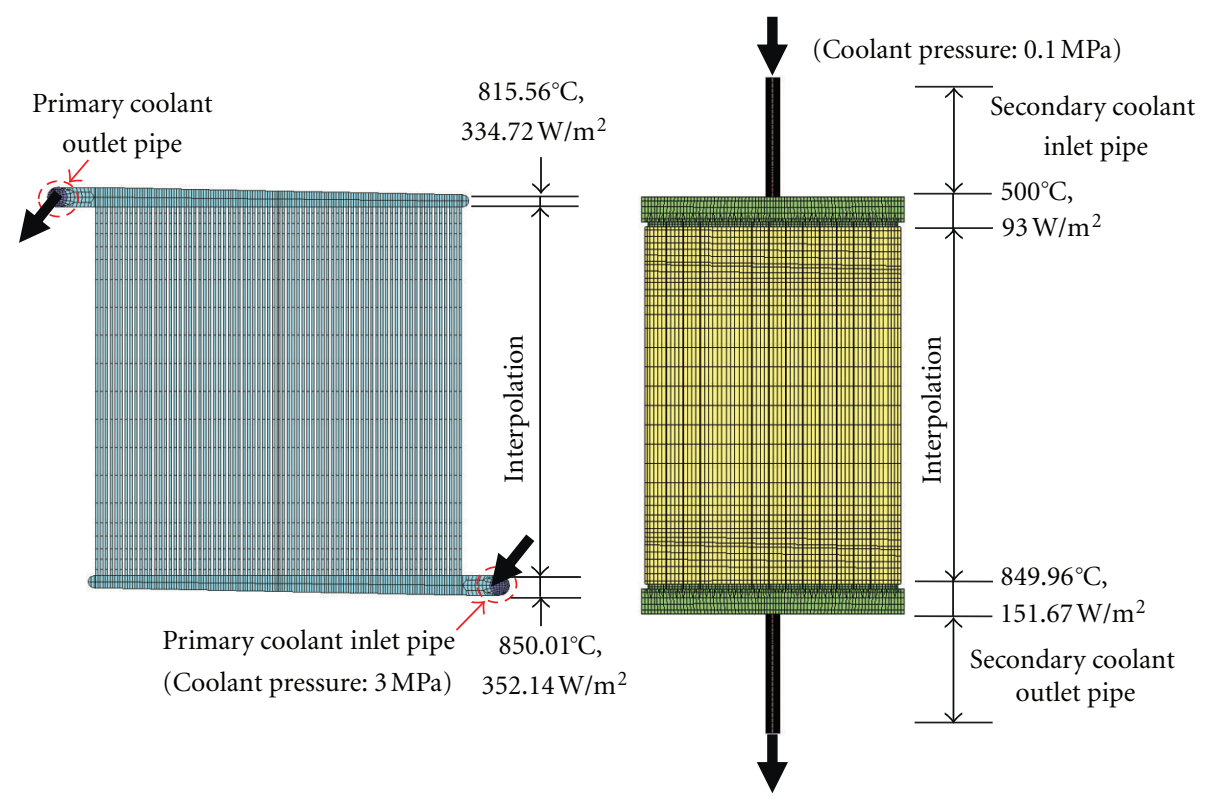

(a)

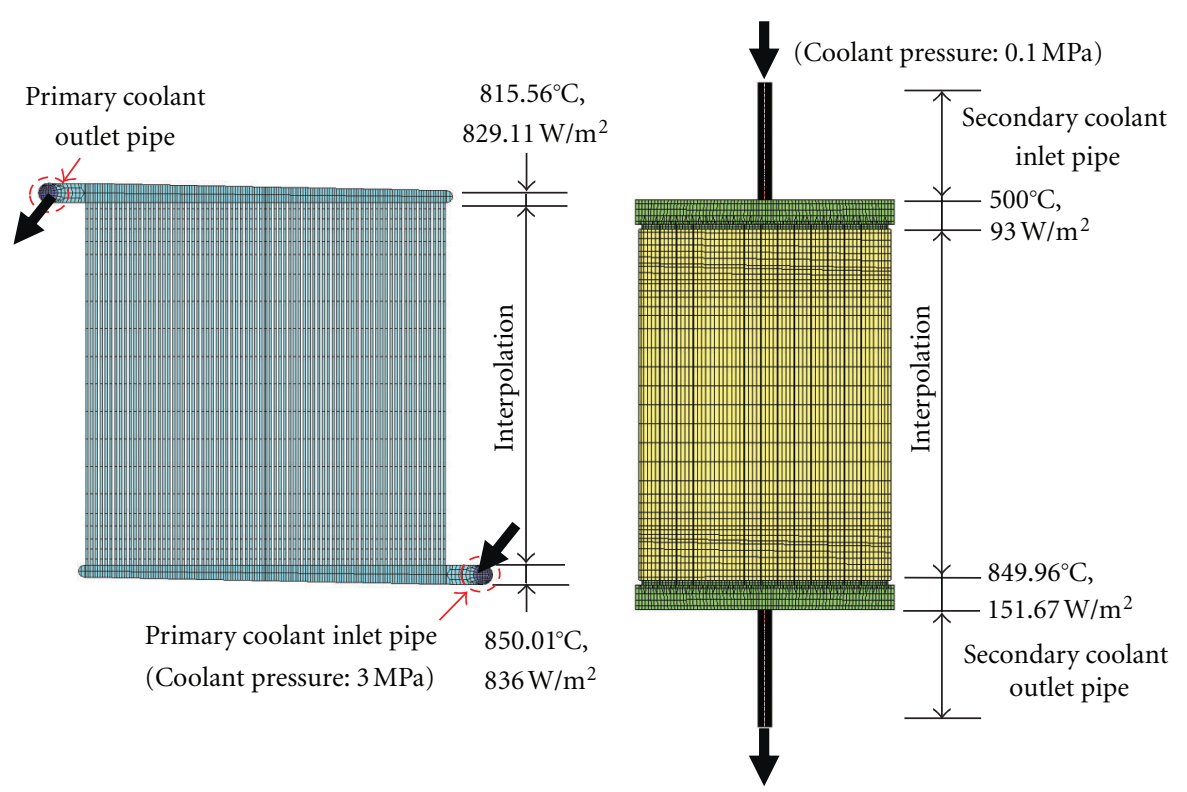

(b)

FigURE 7: Boundary conditions of primary/secondary coolant for a thermal analysis: (a) $3 \mathrm{~kW}$ class PHE prototype and (b) $10 \mathrm{~kW}$ class PHE prototype.

\section{Finite Element Modeling}

Finite element (FE) modeling is carried out using the commercial code, I-DEAS. For the sake of simplicity and an understanding of the overall behavior of the plate-type PHE prototypes, the FE models are formulated with linear solid elements including brick elements, wedge elements, and tetrahedron elements. The structural FE model of the $3 \mathrm{~kW}$ class PHE prototype is formulated using 830,304 brick elements, whereas the structural FE model of the $10 \mathrm{~kW}$ class PHE prototype is formulated using 870,696 brick elements. The weld zone including the weld bead (or fusion zone or weld) and HAZ of the plate-type PHE prototypes are modeled as shown in Figure 6, where the weld bead along the edges of the prototypes and the HAZ of the inner weld bead are represented. However, the chamfering (or rounding) along the edge of the prototypes is not considered in the FE model for the sake of simplicity.

Figure 7 shows the input data of the primary/secondary flow plates for a thermal analysis under a gas loop test condition of $850^{\circ} \mathrm{C}[6,12]$, and Figure 8 shows the displacement constraint conditions considering the pipeline stiffness of the small-scale nitrogen gas loop [13]. 


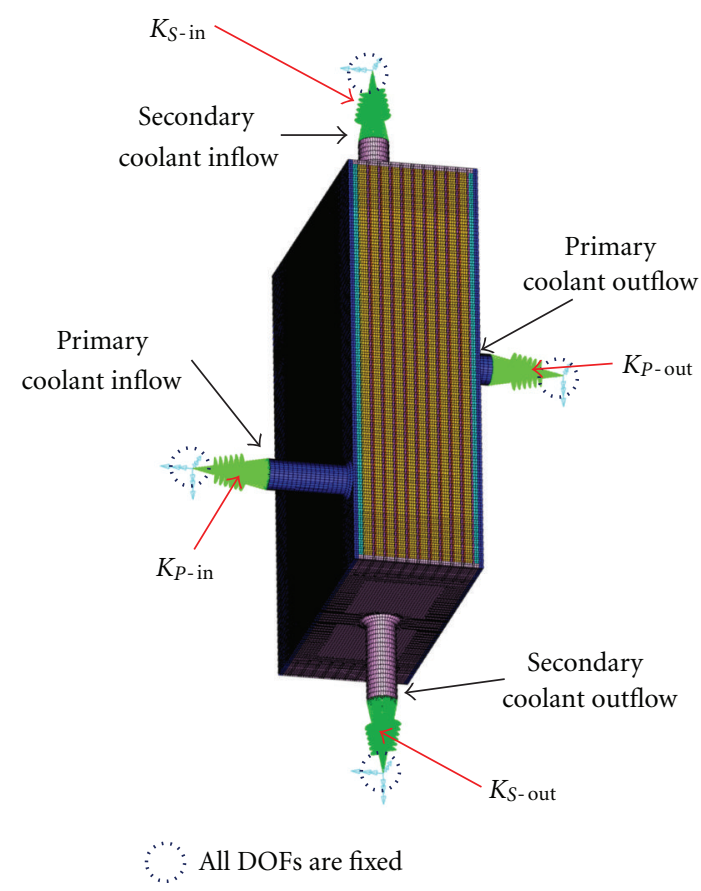

FIGURE 8: Boundary conditions for a structural analysis.

\section{Thermal/Strength Analysis and Discussion}

4.1. Thermal Analysis. Based on the input data shown in Figure 6 and the material properties of Hastelloy-X alloy in Table 2, thermal analyses are carried out using I-DEAS/TMG Ver. 6.1 [14]. Figure 9 shows the steady-state thermal analysis results $[6,12]$ of the plate-type PHE prototypes under the test condition of a small-scale nitrogen gas loop. According to Figure 9, the temperature distributions are nearly symmetrical along the vertical axis owing to external thermal convection and the effects of gravity.

4.2. Structural Analysis. Based on the steady-state thermal analysis results and imposing the displacement constraint conditions shown in Figure 8, steady-state thermostructural analyses on the $\mathrm{PHE}$ prototypes are carried out using ABAQUS Ver. 6.8 [15]. The mesh patterns in the FE models including the node and element numbering are identical for I-DEAS and ABAQUS. The material properties in Table 2 are used as the parent material properties, while the mechanical properties in the weld and HAZ are generated by multiplying the parent material properties with the normalizing factors in Table 3. According to the test conditions of the small-scale nitrogen gas loop, the in/outflow pressures for the primary and secondary coolant are 3.0 $\mathrm{MPa}$ and $0.1 \mathrm{MPa}$, respectively, as shown in Figure 7. The bilinear stress-strain curve of Hastelloy-X for an elastic-plastic structural analysis extracted from a website [11] is shown in Figure 10.

4.2.1. Analysis Results of the $3 \mathrm{~kW}$ Class PHE Prototype. Figure 11 shows the stress distributions from an elastic analysis using the parent material properties. A maximum local stress of 272.33 MPa occurs around the edge between the top plate and side plate, that is, the welded zone, which exceeds the yield stress of the parent material (237.88 MPa at $746^{\circ} \mathrm{C}$ ) [11] by $14.48 \%$. Since the elastic stress distributions using the material properties in the weld zone are the same as those shown in Figure 11 owing to the use of the same elastic modulus in the elastic analysis, the maximum local stress of $272.33 \mathrm{MPa}$ exceeds the yield stress of the weld material (260.24 MPa) by only 4.64\%. Thus, a smaller degree of excess yield stress is attributed to a larger yield stress of the weld material than the parent material.

Figure 12 shows the stress distributions using the parent material properties from an elastic-plastic analysis. A maximum local stress of $242.60 \mathrm{MPa}$ around the edge between the top and side plates, that is, the welded zone, exceeds the yield stress of the parent material $\left(237.63 \mathrm{MPa}\right.$ at $\left.750^{\circ} \mathrm{C}\right)$ by $2.09 \%$. Figure 13 shows the stress distributions using the weld material properties from an elastic-plastic analysis. A maximum local stress of $266.19 \mathrm{MPa}$ exceeds the yield stress of the weld material $\left(260.61 \mathrm{MPa}\right.$ at $\left.740.70^{\circ} \mathrm{C}\right)$ by $2.14 \%$. The degree of excess yield stress on the weld (fusion zone) is changed for the analysis results using the weld material properties as compared to using the parent material properties. This is attributed to a larger yield stress in the weld than in the parent material.

Figure 14 shows the stress distributions on the weld bead and in the HAZ from an elastic-plastic analysis using the weld material properties. In the HAZ, a maximum local stress of $235.47 \mathrm{MPa}$ exceeds the yield stress of the weld material $\left(228.65 \mathrm{MPa}\right.$ at $\left.749.22^{\circ} \mathrm{C}\right)$ by $2.98 \%$, while a maximum stress of $239.17 \mathrm{MPa}$ using the parent material properties exceeds the yield stress of the parent material $(237.68 \mathrm{MPa})$ by only $0.63 \%$. The degree of excess yield stress in the HAZ 


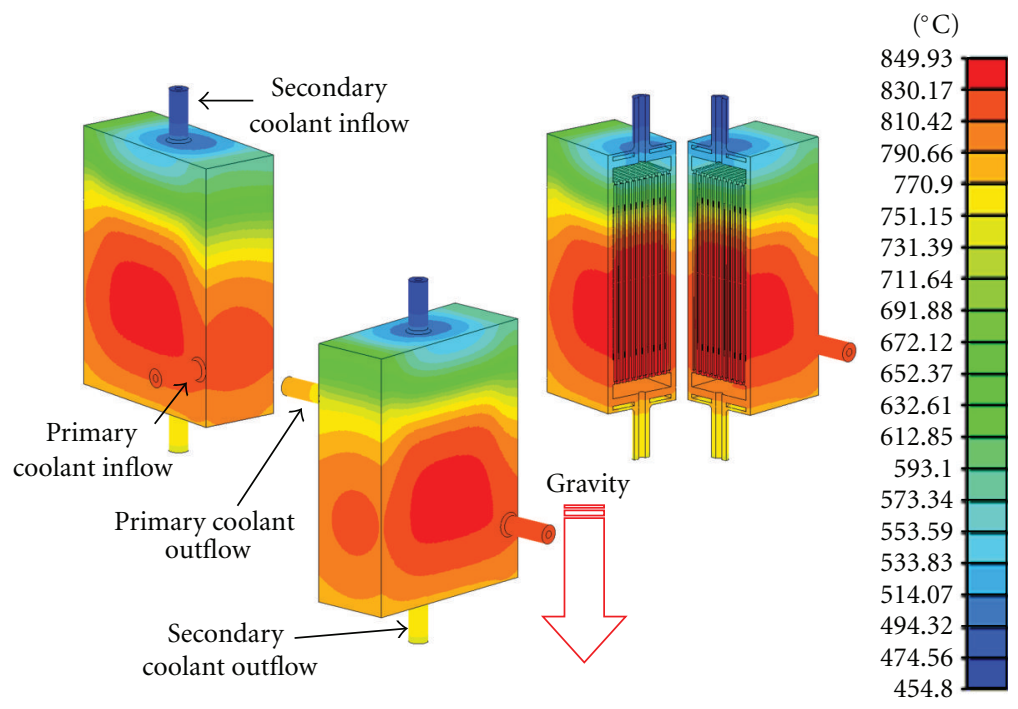

(a)

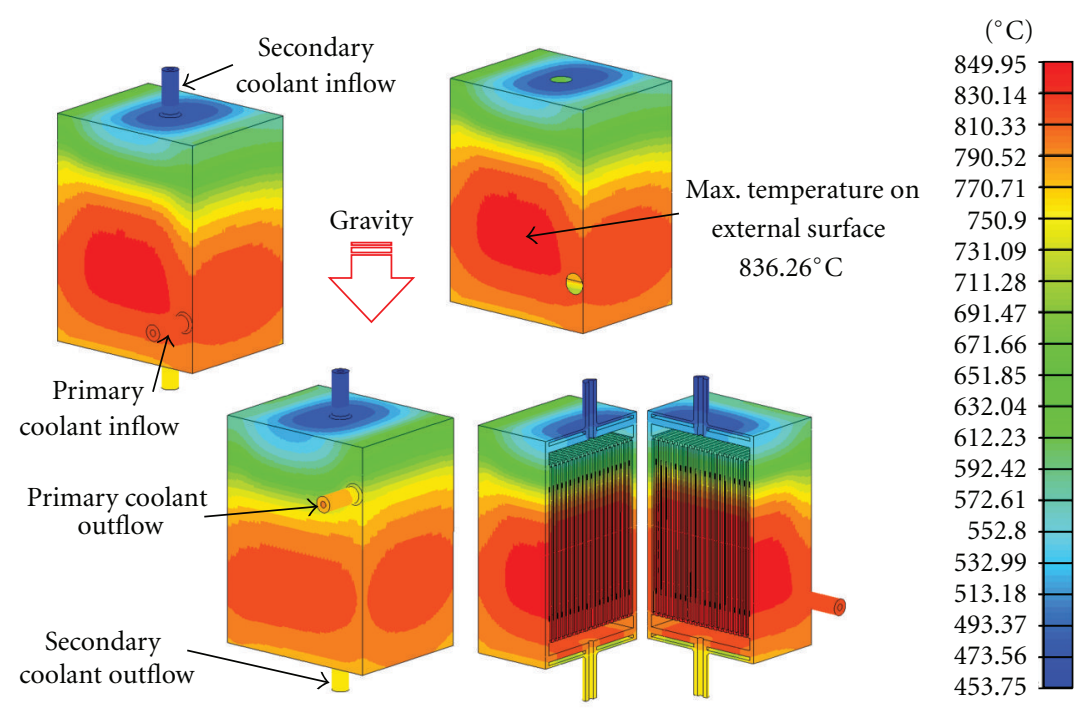

(b)

Figure 9: Temperature contours of outer PHEs: (a) $3 \mathrm{~kW}$ class PHE prototype [6] and (b) $10 \mathrm{~kW}$ class PHE prototype [12].

is increased for the analysis results using the weld material properties compared to using the parent material properties. This is attributed to a smaller yield stress in the HAZ than that in the parent material. The thermostructural analysis results of the $3 \mathrm{~kW}$ class PHE prototype are briefly summarized in Table 5 .

4.2.2. Analysis Results of $10 \mathrm{~kW}$ Class PHE Prototype. Figure 15 shows the stress distributions of the $10 \mathrm{~kW}$ class PHE prototype from an elastic analysis using the parent material properties. A maximum local stress of $331.23 \mathrm{MPa}$ occurs around the edge between the top and side plates, that is, the welded zone, which exceeds the yield stress of the parent material $\left(237.98 \mathrm{MPa}\right.$ at $\left.744.46^{\circ} \mathrm{C}\right)$ by $39.18 \%$. Since the stress distributions using the material properties in the weld zone are the same as those shown in Figure 15 owing to the use of the same elastic modulus in the elastic analysis, the maximum local stress of $331.23 \mathrm{MPa}$ exceeds the yield stress of the weld material ( $260.35 \mathrm{MPa}$ ) by $27.22 \%$. Thus, a smaller degree of excess yield stress is attributed to the larger yield stress of the weld material than the parent material.

Figure 16 shows the stress distributions using the parent material properties from an elastic-plastic analysis. A maximum local stress of $263.65 \mathrm{MPa}$ exceeds the yield stress of the parent material $\left(236.86 \mathrm{MPa}\right.$ at $\left.760.37^{\circ} \mathrm{C}\right)$ by $11.31 \%$. Figure 17 shows the stress distributions using the weld material properties from an elastic-plastic analysis. A maximum local stress of 267.60 MPa occurs around the edge between the top and side plates, that is, the welded zone, which exceeds the yield stress of the weld material $(260.50 \mathrm{MPa}$ at $742.23^{\circ} \mathrm{C}$ ) by $2.72 \%$. The degree of excess yield stress on the weld (fusion zone) is decreased for the analysis results using 
TABLE 5: Analysis results of $3 \mathrm{~kW}$ class PHE prototype.

\begin{tabular}{|c|c|c|c|c|c|c|c|c|c|}
\hline & \multicolumn{3}{|c|}{ Maximum local stress } & \multicolumn{3}{|c|}{ Yield stress (MPa) } & \multicolumn{3}{|c|}{$\begin{array}{l}\text { Percentage exceeding the } \\
\text { yield stress }(\%)\end{array}$} \\
\hline & Stress $(\mathrm{MPa})$ & Location & Temperature $\left({ }^{\circ} \mathrm{C}\right)$ & Parent & Weld & HAZ & Parent & Weld & HAZ \\
\hline Elastic analysis & 272.33 & Weld & 746.00 & 237.88 & 260.24 & & 14.48 & 4.64 & \\
\hline \multicolumn{10}{|l|}{ Elastic-plastic analysis } \\
\hline \multicolumn{10}{|l|}{ Weld } \\
\hline Using parent material properties & 242.60 & Weld & 750.00 & 237.63 & & & 2.09 & & \\
\hline Using weld material properties & 266.19 & Weld & 740.70 & 260.61 & & & & 2.14 & \\
\hline \multicolumn{10}{|l|}{ HAZ } \\
\hline Using parent material properties & 239.17 & HAZ & & & & 237.68 & 0.63 & & \\
\hline Using weld material properties & 235.47 & HAZ & 749.22 & & & 228.65 & & & 2.98 \\
\hline
\end{tabular}

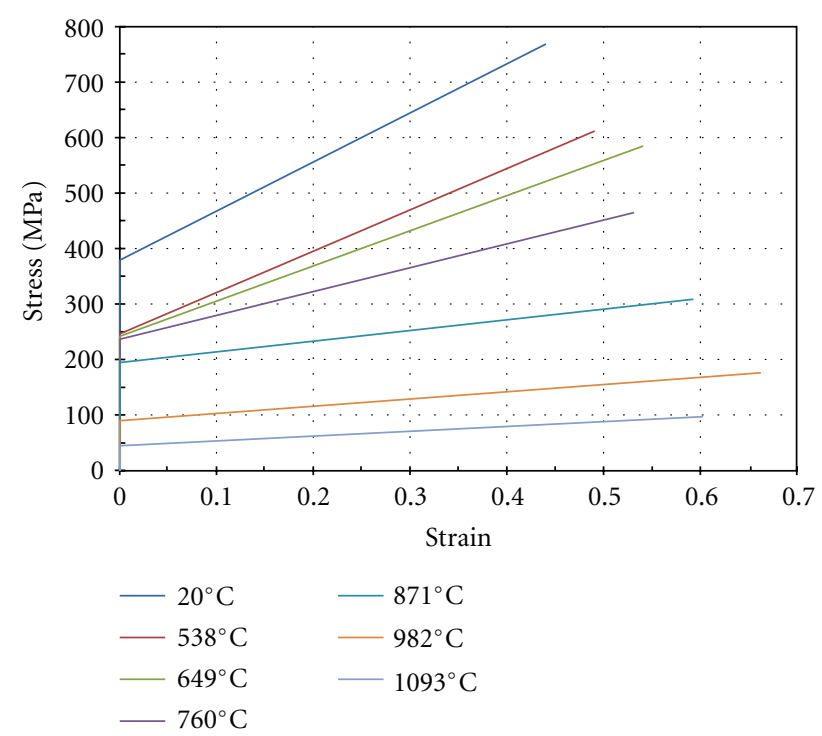

FIgURE 10: Bilinear stress-strain curve for an elastic-plastic analysis [10].

S, Mises MPa
(Avg.: $75 \%)$
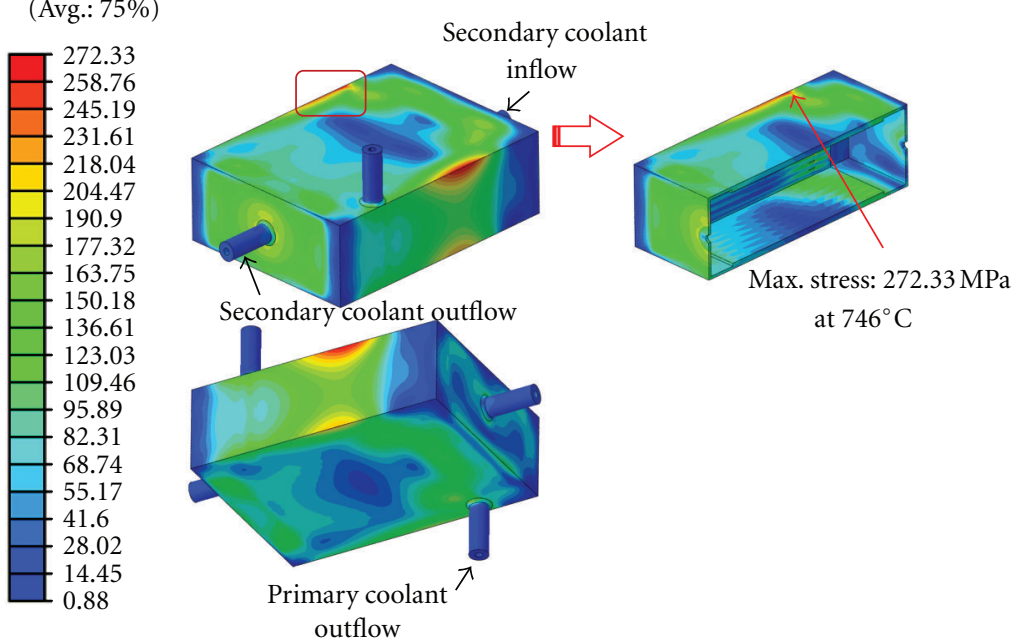

FIGURE 11: Overall stress contours of a $3 \mathrm{~kW}$ class PHE prototype from an elastic analysis using the parent material properties [6]. 


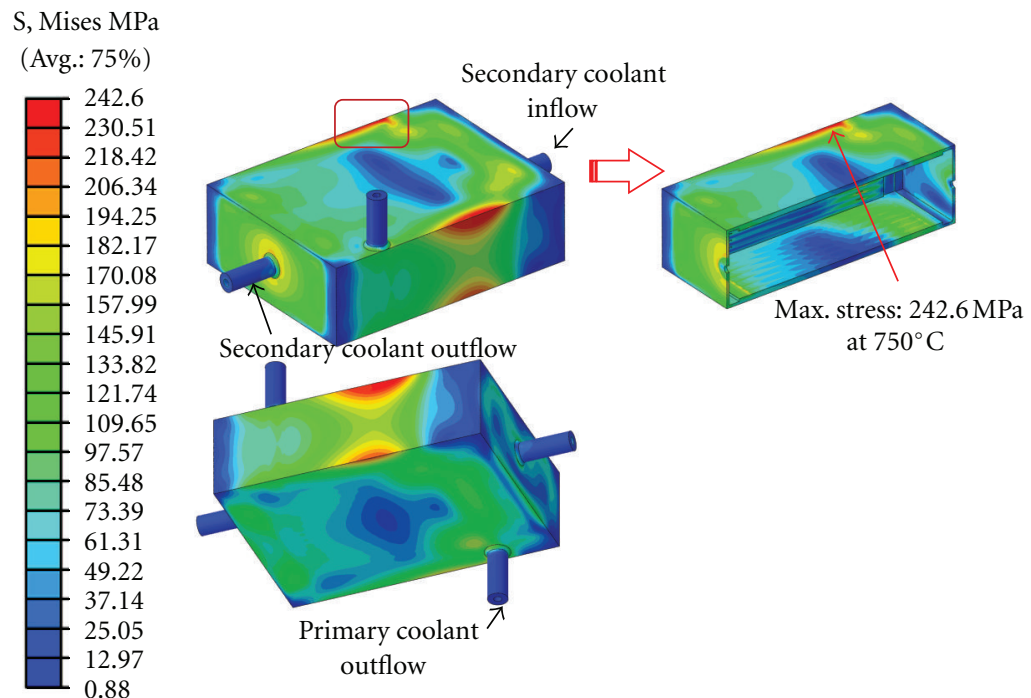

FIGURE 12: Overall stress contours of a $3 \mathrm{~kW}$ class PHE prototype from an elastic-plastic analysis using the parent material properties [6].

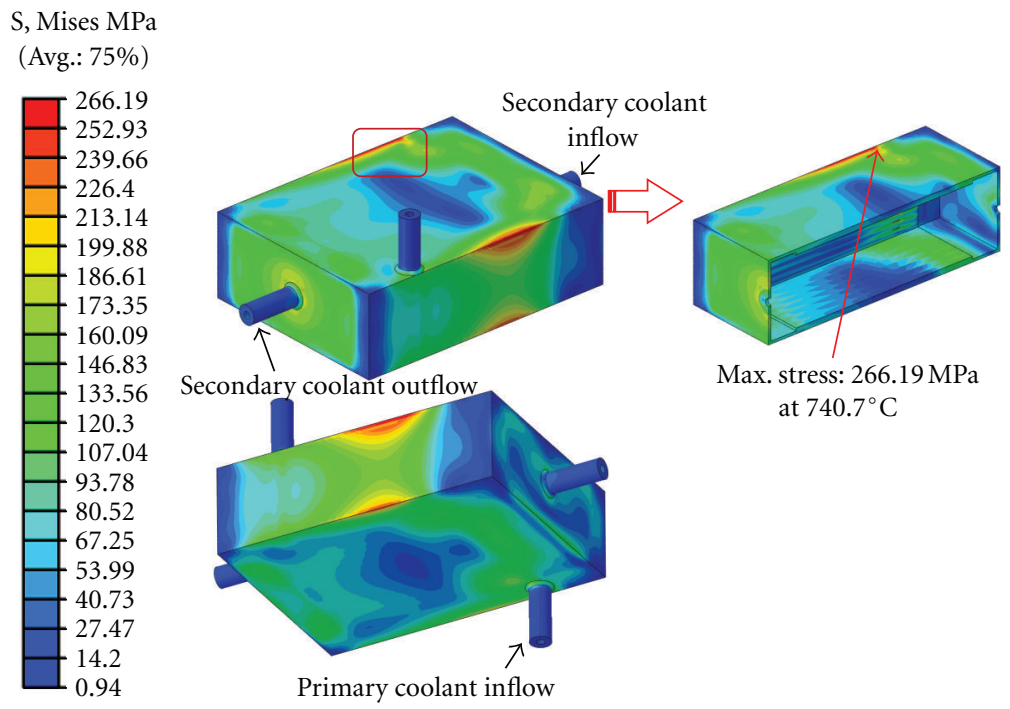

FIGURE 13: Overall stress contours of a $3 \mathrm{~kW}$ class PHE prototype from an elastic-plastic analysis using the weld material properties.

the weld material properties compared to using the parent material properties. This is attributed to a larger yield stress in the weld than in the parent material.

Figure 18 shows the stress distributions on the weld bead and in the HAZ from an elastic-plastic analysis using the weld material properties. In the HAZ, a maximum local stress of $264.56 \mathrm{MPa}$ exceeds the yield stress of the weld material $\left(216.04 \mathrm{MPa}\right.$ at $\left.792.09^{\circ} \mathrm{C}\right)$ by $22.46 \%$, while a maximum stress of $191.88 \mathrm{MPa}$ using the parent material properties is smaller than the yield stress of the parent material $(224.57 \mathrm{MPa})$ by $14.56 \%$. The degree of excess yield stress in the HAZ is increased for the analysis results using the weld material properties compared to using the parent material properties. This is attributed to a smaller yield stress in HAZ than that in the parent material. The thermostructural analysis results of the $10 \mathrm{~kW}$ class PHE prototype are briefly summarized in Table 6.
4.3. Discussions. From the results of the thermostructural analyses on the plate-type PHE prototypes, the following interesting observation was found. Even though the maximum stress exceeds the yield stress in the weld zone, the degree of excess yield stress decreases or increases owing to the different yield stresses in the weld zone, when compared with the analysis results of using the parent material properties. Consequently, a thermostructural analysis considering the weld material properties seems to be needed to understand the structural behavior and evaluate the structural integrity of the plate-type PHE prototypes more reliably.

A higher amount of stress and wider high-stress region occur for the $10 \mathrm{~kW}$ PHE prototype compared to the $3 \mathrm{~kW}$ PHE prototype. This is attributed to the size effect of the prototypes under the same displacement constraint conditions. 
TABLE 6: Analysis results of $10 \mathrm{~kW}$ class PHE prototype.

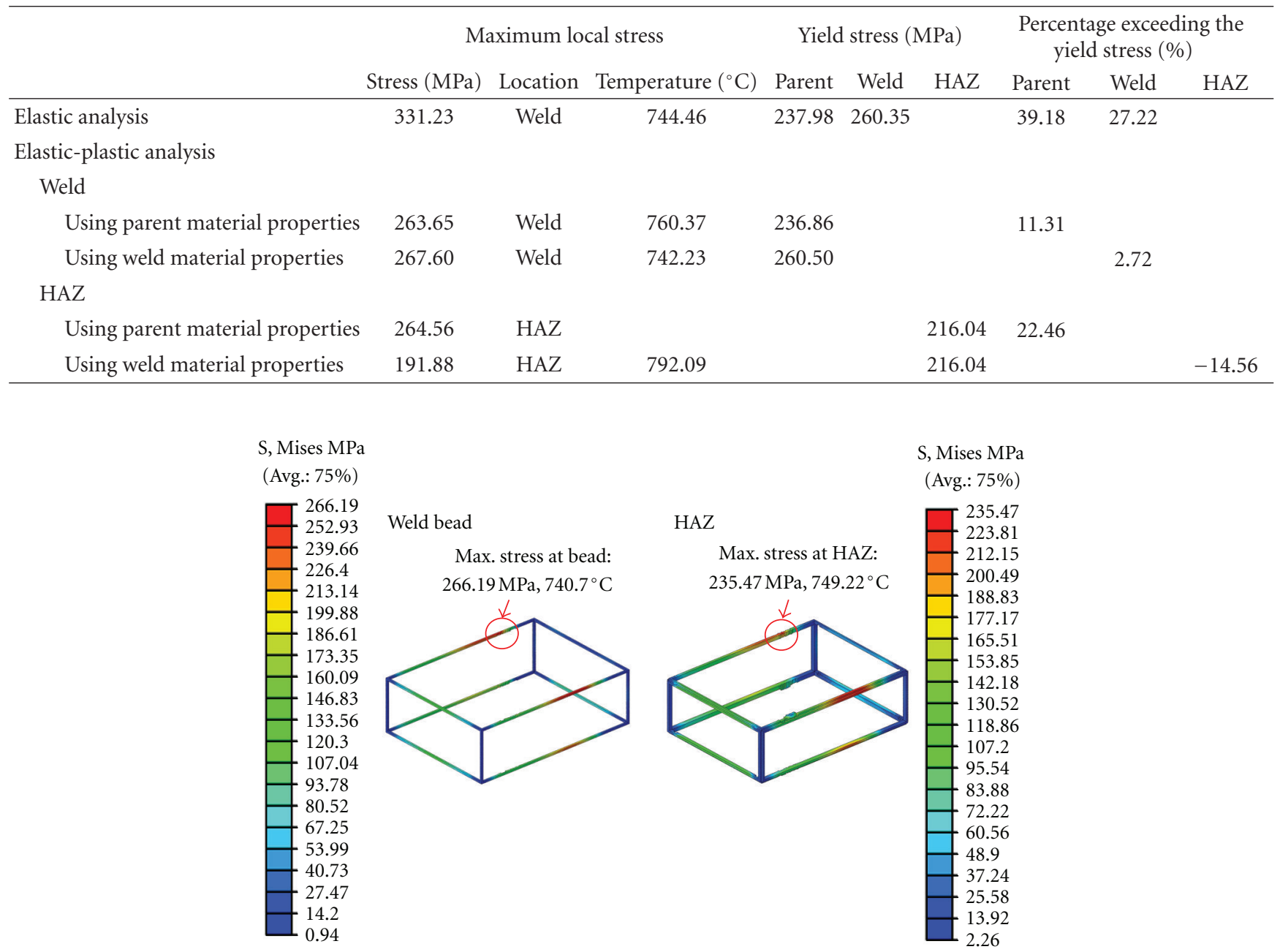

FIGURE 14: Stress contours of a $3 \mathrm{~kW}$ class PHE prototype in the weld zone from an elastic-plastic analysis using the weld material properties.
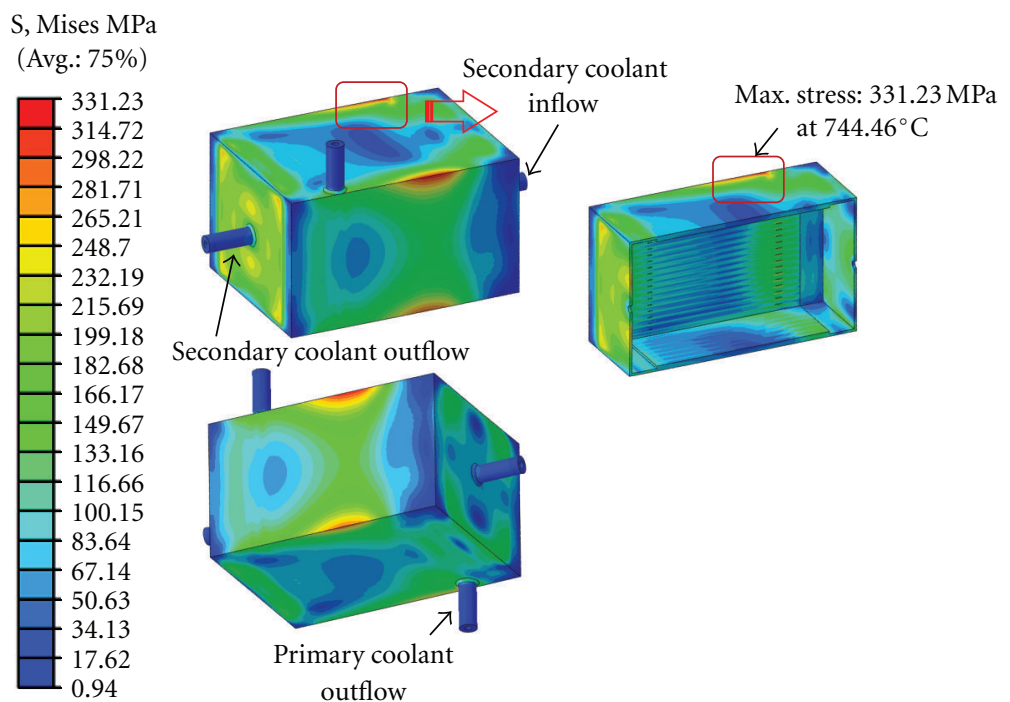

Figure 15: Overall stress contours of a $10 \mathrm{~kW}$ class PHE prototype from an elastic analysis using the parent material properties [12]. 


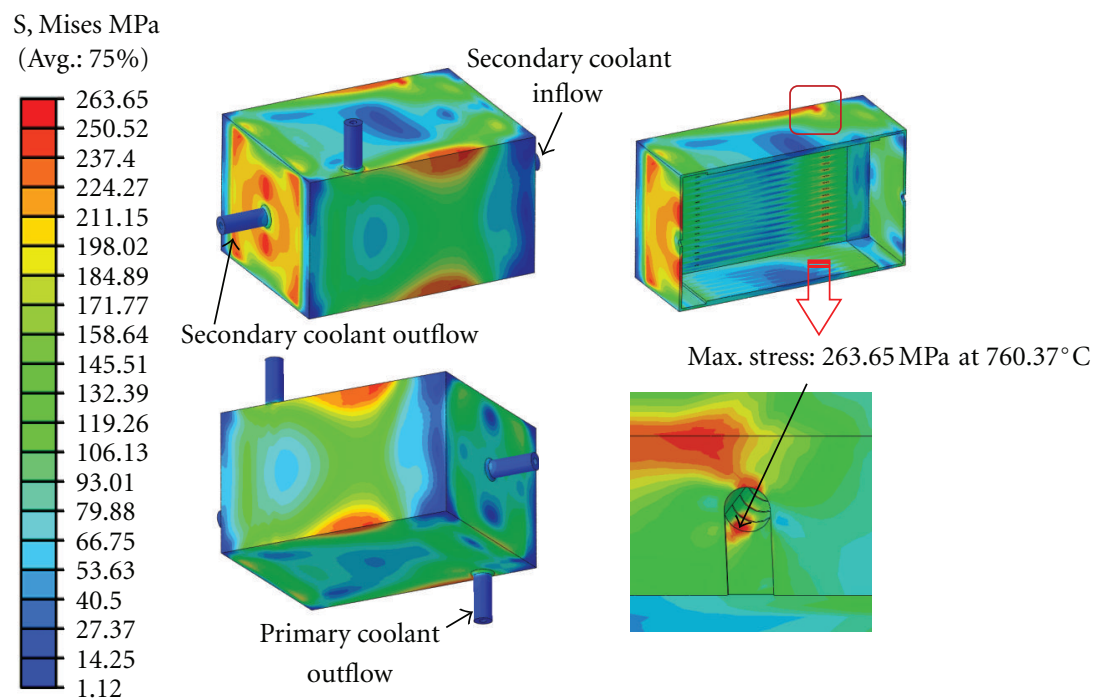

FIGURE 16: Overall stress contours of a $10 \mathrm{~kW}$ class PHE prototype from an elastic-plastic analysis using the parent material properties [12].

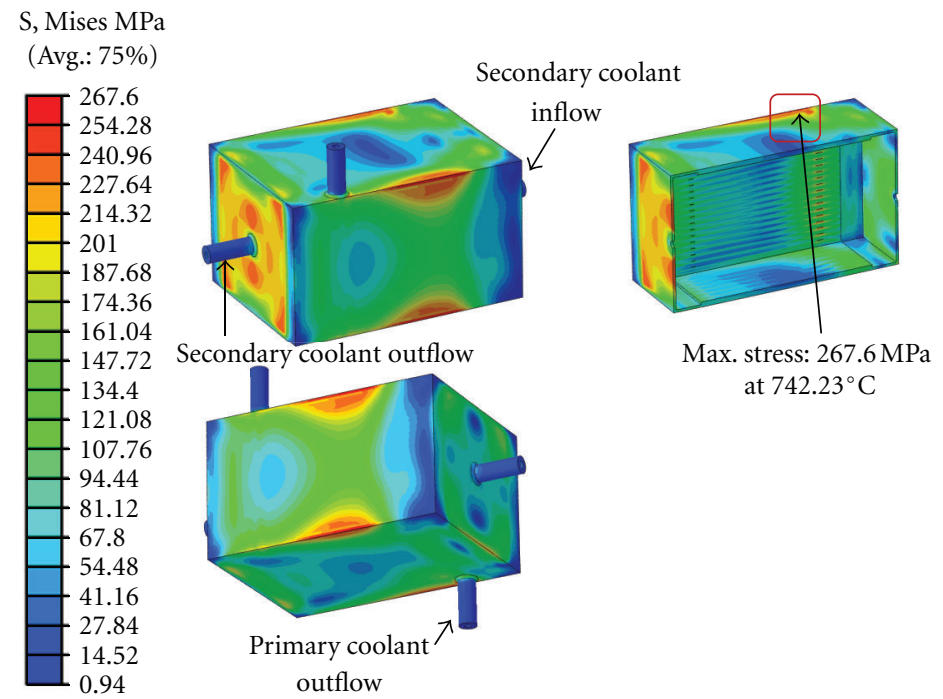

FIGURE 17: Overall stress contours of a $10 \mathrm{~kW}$ class PHE prototype from an elastic-plastic analysis using the weld material properties.

The maximum local stress occurs around the edge between the top and side plates of the plate-type PHE prototypes, that is, the welded zone. The stress that occurs around the edges in the FE model will decrease to a certain degree when considering the chamfered edges, since the edges of the PHE prototypes are chamfered realistically.

\section{Conclusions}

In this study, to investigate the effects of the weld material properties on the mechanical behavior of plate-type PHE prototypes made of Hastelloy-X, thermostructural analyses considering the weld mechanical properties were performed and the results were compared with those using the parent material properties. As a result of the analysis, the following conclusions can be drawn.
(1) While the maximum stress exceeds the yield stress in the weld zone, the degree of excess yield stress may differ owing to the different yield stresses in the weld zone.

(2) A thermostructural analysis considering the weld material properties seems to be necessary to understand the structural behavior and evaluate the structural integrity of the plate-type PHE prototypes more reliably.

(3) The stress occurring around the edges in the FE model will decrease to a certain degree when considering the chamfered edges, since the edges of the PHE prototypes are chamfered realistically. 

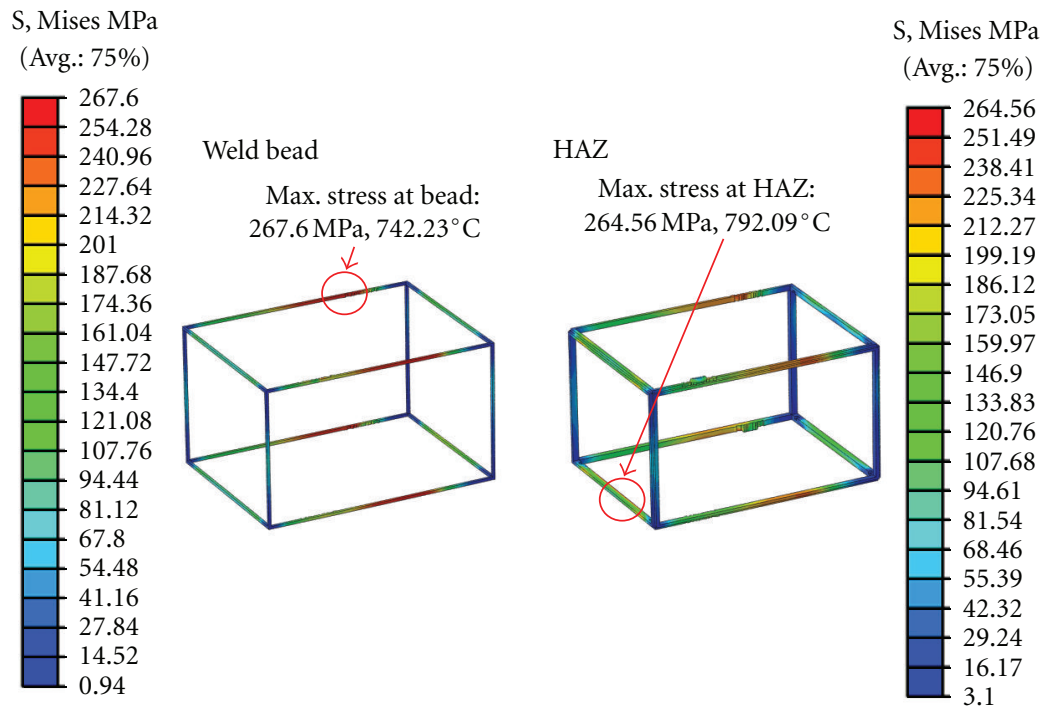

Figure 18: Stress contours of a $10 \mathrm{~kW}$ class PHE prototype in weld zone from an elastic-plastic analysis using the weld material properties.

\section{References}

[1] Y. W. Kim et al., Development of essential technology, KAERI/RR-2992/2008, Korea Atomic Energy Research Institute, 2009.

[2] E. George Linnert, Welding Metallurgy 1, American Welding Society, New York, NY, USA, 1965.

[3] K. N. Song, H. Y. Lee, C. S. Kim, S. D. Hong, and H. Y. Park, "High-temperature structural analysis model of the process heat exchanger for helium gas loop (II)," Transactions of the Korean Society of Mechanical Engineers A, vol. 34, no. 10, pp. 1455-1462, 2010 (Korean).

[4] K. N. Song, H. Y. Lee, S. D. Hong, and H. Y. Park, "High-Temperature structural analysis on the small-scale PHE prototype," Transactions of the Korean Society of Pressure Vessels and Piping, vol. 6, pp. 57-64, 2011 (Korean).

[5] K. N. Song, H. Y. Lee, C. S. Kim, S. D. Hong, and H. Y. Park, "High-temperature structural analysis of small-scale prototype of process heat exchanger (III)," Transactions of the Korean Society of Mechanical Engineers A, vol. 35, no. 2, pp. 191-200, 2011 (Korean).

[6] K. N. Song, S. D. Hong, and H. Y. Park, "High-Temperature structural analysis of a small-scale prototype of a process heat exchanger (IV)," Transactions of the Korean Society of Mechanical Engineers A, vol. 35, pp. 1249-1255, 2011 (Korean).

[7] K. N. Song, S. D. Hong, and H. Y. Park, "High-Temperature structural analysis on the small-scale prototype under the test condition of small-scale gas loop," Transactions of the Korean Society of Pressure Vessels and Piping, vol. 8, pp. 1-7, 2012.

[8] I. S. O. TR29381, "Metallic materials—instrumented indentation test for measurement of indentation tensile properties," 2008.

[9] K. N. Song and D. S. Ro, "Measurement of mechanical properties in weld zone of nuclear material using an instrumented indentation technique," Journal of the Korean Welding \& Joining Society, vol. 30, no. 3, pp. 249-254, 2012 (Korean).

[10] K. N. Song, S. D. Hong, S. H. Lee, and H. Y. Park, "Effect of mechanical properties in the weld zone on the structural analysis results of a plate-type heat exchanger prototype and pressurized water reactor spacer grid," Journal of Nuclear Science and Technology, vol. 49, pp. 947-960, 2012.

[11] X. Hastelloy- alloy, 2012, http://www.haynesintl.com/pdf/ h3009.pdf.

[12] K. N. Song, S. D. Hong, and H. Y. Park, "High-temperature structural analysis on a medium-scale PHE prototype," Transactions of the Korean Society of Mechanical Engineers A, vol. 36, pp. 1283-1288, 2012 (Korean).

[13] K. N. Song, S. D. Hong, and H. Y. Park, "High-temperature structural analysis of a small-scale PHE prototype under the test condition of a small-scale gas loop," Science and Technology of Nuclear Installation, vol. 2012, Article ID 312080, 10 pages, 2012.

[14] Siemens PLM software I-DEAS/TMG User Manual Version 6. $1,2009$.

[15] Dassault Systemes Simulia ABAQUS Analysis User Manual Version 6. 9-1, 2009. 

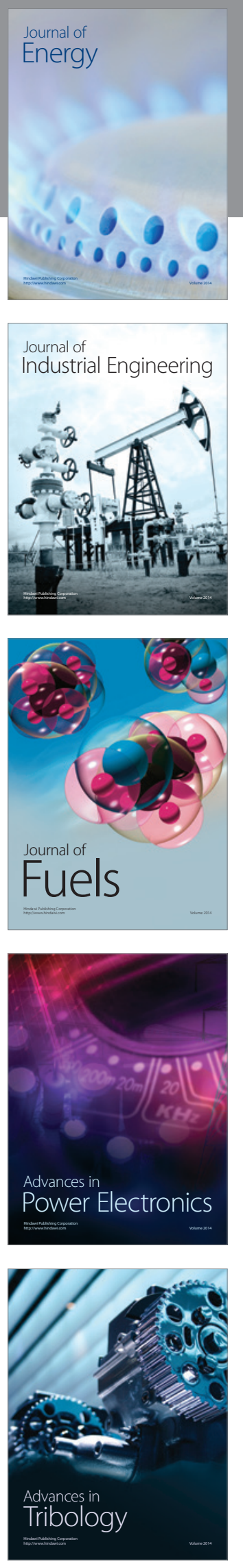
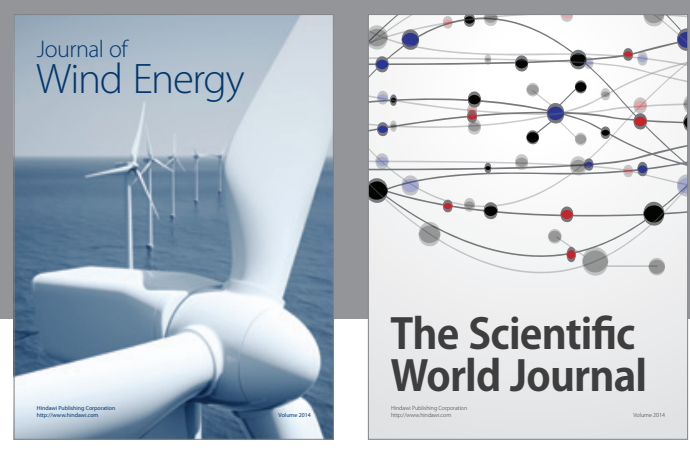

The Scientific World Journal

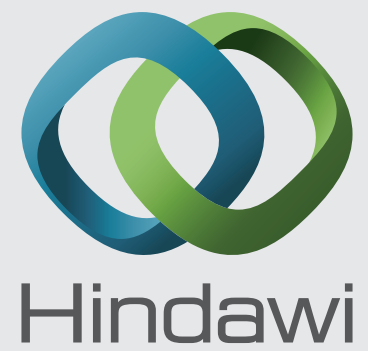

Submit your manuscripts at http://www.hindawi.com
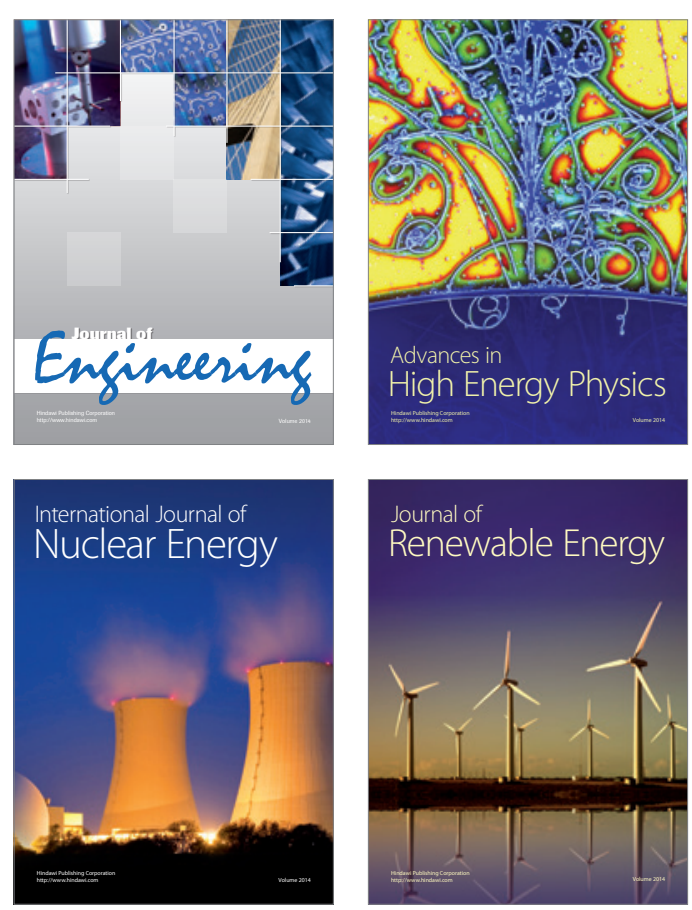

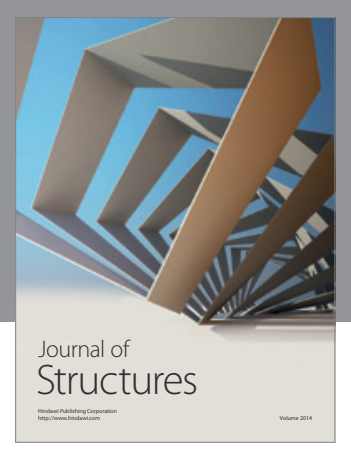

Rotating
Mechinery
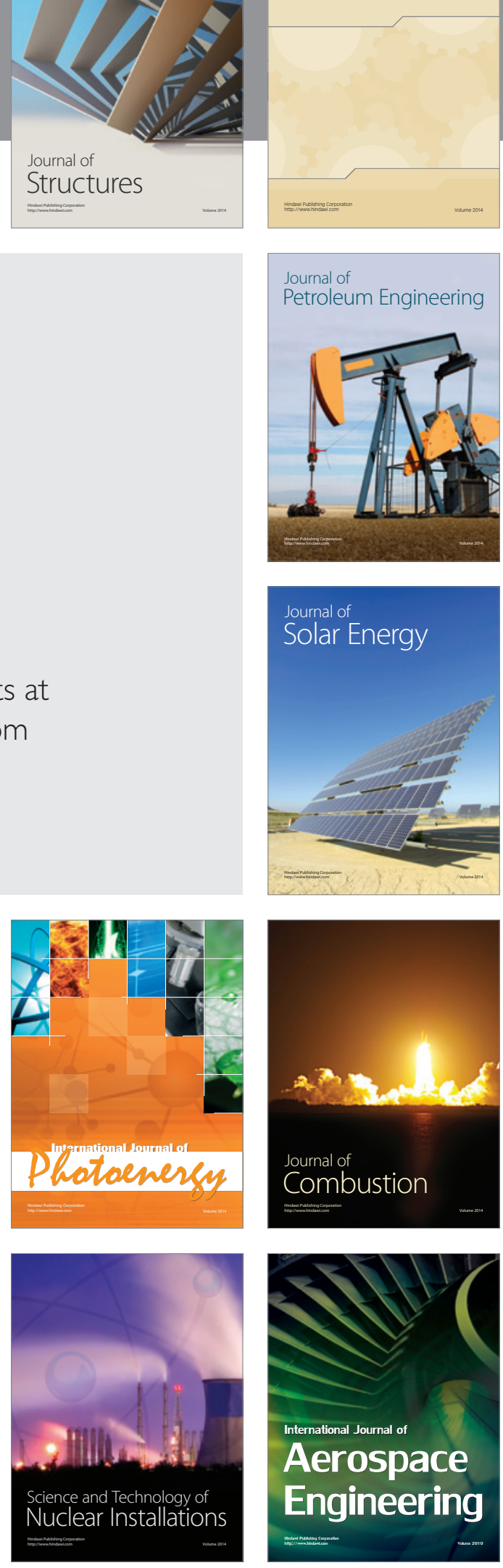